\title{
Performance evaluation of wireless sensor networks using LEACH protocol
}

\author{
Anas Ali Hussien ${ }^{1}$, Shaymaa W. Al-Shammari ${ }^{2}$, Mehdi J. Marie ${ }^{3}$ \\ ${ }^{1,2}$ Department of Computer Engineering, Al-Nahrain University, Iraq \\ ${ }^{3} \mathrm{Al}$-Zawraa State Co., Ministry of Industry and Minerals, Iraq
}

\begin{tabular}{|c|c|}
\hline Article Info & ABSTRACT \\
\hline Article history: & \multirow{8}{*}{$\begin{array}{l}\text { Recent days witnessed considerable developments in the field of wireless } \\
\text { sensor networks (WSNs). The applications of these networks can be seen in } \\
\text { the simple consumer electronic devices as well as in the advanced space } \\
\text { technology. The communication protocols are of prior importance and } \\
\text { interest; the low-energy adaptive clustering hierarchy (LEACH) protocol is } \\
\text { used to enhance the performance of power consumption for the WSNs nodes. } \\
\text { The efficiency of a wireless network can be affected by different factors, } \\
\text { such as the size of the WSN and the initial energy of the sensor node. This } \\
\text { can inspire the researchers to develop the optimum structure of the WSNs to } \\
\text { get its desired functionality. In this paper, the performance of the low-energy } \\
\text { adaptive clustering hierarchy (LEACH) protocol is investigated using } \\
\text { MATLAB to study the effect of the initial energy of the sensor node and } \\
\text { the WSN size on the number of the running nodes. It is found that increasing } \\
\text { the initial energy of a sensor node increases the life time of the node and } \\
\text { hence the number of the running nodes. It has been also approved that the } \\
\text { WSN size has an inverse proportion with the number of running sensor nodes } \\
\text { during the use of LEACH protocol. }\end{array}$} \\
\hline Received Nov 1, 2019 & \\
\hline Revised Dec 10, 2019 & \\
\hline Accepted Jan 8, 2020 & \\
\hline Keywords: & \\
\hline LEACH Protocol & \\
\hline Performance & \\
\hline WSN & \\
\hline
\end{tabular}

Copyright (C) 2020 Institute of Advanced Engineering and Science. All rights reserved.

\section{Corresponding Author:}

Anas Ali Hussien,

Department of Computer Engineering,

Al-Nahrain University, Baghdad, Iraq.

Email: anasali78@yahoo.com

\section{INTRODUCTION}

Wireless Sensor Networks have been employed in managing different and critical situations in life. To deal with the problems of energy consumption in WSN, the researchers have used many techniques in which they have suggested that Cluster Head $\mathrm{CH}$ should be chosen to forward the data of the nodes [1-3]. LEACH protocol is a hierarchical protocol; this protocol allows the sensor nodes to send data to the cluster heads of the cluster that they belong to. The cluster heads collect and aggregate the received data from the other nodes in the cluster and then forward it to the sink, which is called the base station. This protocol aims to increase the lifetime of the wireless sensor nodes. The overall operation of the LEACH protocol is based on the rounds, where each round consists of two stages, the first is the "set up stage", while the second is the "steady state" stage. "Setup phase" operation consists of creating the cluster and to choose a $\mathrm{CH}$ for corresponding cluster. The "steady phase" involves the transmission of the collected information by the $\mathrm{CH}$ to the base station (sink). The architecture of LEACH protocol is represented in Figure 1. LEACH helps to balance energy consumption of the sensor nodes [4-9].

For the homogeneous cluster based network, the cluster heads as in LEACH are chosen randomly to act as relay nodes to transmit the data; then the cluster heads exchange their roles with normal nodes to consume a uniform energy of all the nodes. Because of the proposed hybrid technique, the lifetime of nodes 
increases and decreases the transmission energy consumption. The aim of the WSN is to transmit data continuously and to maximize the network coverage [10-18].

Many points should be taken into consideration that can affect the efficiency of routing of LEACH protocol, such as the life time of the sensor node that can be affected by the energy consumption in both the communication and computation, another factor is the coverage of nodes in the network area that includes both sensor and communication coverage, the scalability of the number of sensor nodes. Attention should be also paid to the performance metrics like network life time [18-20]. The continious decrease of the nodes energy is one of the disadvantages of the LEACH protocol, this is due to the communication occur among the nodes [21,22].

The aforementioned points had motivated the authors to consider these factors in studying the performance of the wireless sensor network. So, the aim of this paper is to study the effect of the sensor node's initial energy and network size on the number of the running nodes and the consumed energy of the WSN. The importance of the study comes from being a reference that can inspire the researchers in the filed to develop the optimum structure of the WSNs in order to get its desired functionality.

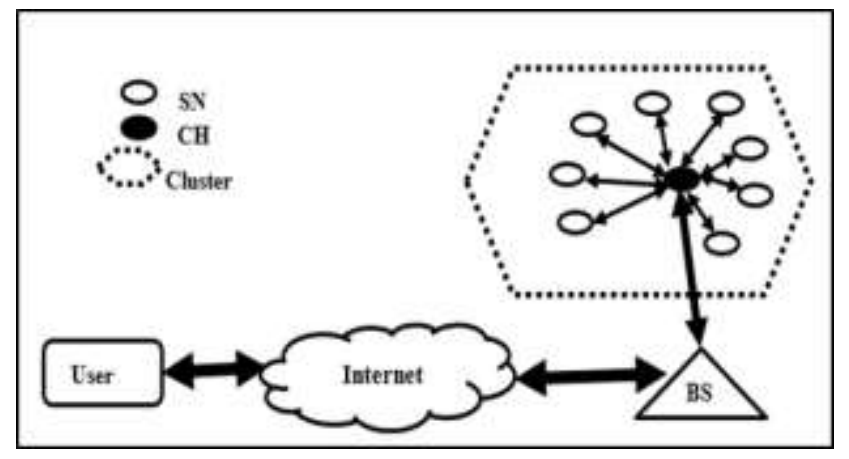

Figure 1. Hierarical wireless sensor network architecture [6]

Studying the performance of the WSN taking into consideration the consumed energy has been considered by many researchers. Malik et al. (2013) studied the performance of LEACH protocol in WSN, the authors considered studying the performance as a result of changing the number of the cluster heads [23]. Sharma and Kumar (2017) presented a study of energy consumption using qualitative evaluation and channel probing [24] the presented study measured the consumed energy. The research performed by Elhoseny et al. (2017) introduced a performance evaluation for the LEACH protocol for a proposed method to elect the $\mathrm{CH}$ in the WSN [25]. However, the reported results in these researches lacked considering the effect of changing the network size or the initial energy of the used sensor nodes. The dissipated energy in the transmitter and receiver circuits in LEACH protocol needed to transmit a message composed of k-bits can be defined by the following formulas [4]:

$$
\begin{aligned}
& \text { ETx }(k, d)=k * \text { Eelec }+k * \text { Eamp } * d 2 \quad d<0 \\
& =k * \text { Eelec }+k * \text { Eamp } * d 4 \quad d \geq 0
\end{aligned}
$$

where $\mathrm{d}$ is the distance, $\mathrm{E}_{\text {elec }}$ is the consumed energy in the transmitter circit, $E_{a m p}$ is the consumed energy in the amplifier used to maintain reliable signal.

The rest of this paper is organized as follows, an introduction to the WSN system model is presented in section 1, section 2 presents the proposed model and mathematical models, section 3 discusses the obtained simulation results, the main conclusions are presented in section 4 .

\section{PROPOSED WSN SYSTEM MODEL}

In order to model the LEACH protocol, the following assumptions are taken into consideration. The sensor nodes and the sink are all stationary after deployment. The sensor nodes are distributed uniformly and randomly in the network field. The sensors are homogeneous with the same capabilities. The sensor nodes are battery powered; therefore, have limited energy. And the suggested sensor nodes can calculate their residual energy. 
A set of sensor nodes $\mathrm{Sn}$ and a sink node in the network was considered. Each sensor node has the location information $(x, y)$. The sleep mode is used for the sensor node to conserve the energy. The communication is accomplished between the sensor nodes using the LEACH protocol. The sink node possesses unlimited computation, memory, and battery power. The sink node also contains the identity and location of each sensor node. When the sink requires the data from the source node, it constructs the route between them.

\section{SIMULATION RESULTS}

This section introduces the simulation of the system, which is done using Matlab 2018 to evaluate the LEACH protocol using comparative analysis among different senarios. It is assumed that the homogenous sensor network is considered to be in the centre of the WSN, so in the case of 100x100 network, the sink will be in the $(x=50, y=50)$ coordinates, and for the case of 50x50 network, the sink will be in the $(\mathrm{x}=25 \mathrm{y}=25)$ and in the case of $150 \mathrm{x} 150$ network, the sink will be in the $(\mathrm{x}=75, \mathrm{y}=75)$. This research considered studying the behaviour of the WSN taking into consideration many scenarios. This includes reviewing the effect of changing the initial energy of the sensor nodes on the number of the running nodes per rounds and transmission, in addition to the energy consumed in each scenario. The study also introduced studying the effect of changing the size of the wireless sensor network on the running nodes taking into consideration many scenarios.

The results are discussed for each scenario. The simulation parameters involve the following: the data packet size is 512 bytes, the energy of both the transmitter and receiver is 50 nano Joule/bit, and the energy spent by the amplifier is 100 pico Joule / bit.

\subsection{The effect of changing the initial energy}

The following scenarios are considered to consider the effect of changing the initiual energy on the number of running nodes/rounds, number of running nodes/transmission, in addition to the comsumed energy. Table 1 summarises the results obtained in each scenario.

Scenario 1: (running nodes 100) network size 100x100:

This scenario presents the results obtained in the case of changing the initial energy in the case of considering 100 sensor nodes in the field and in the case of $100 \times 100 \mathrm{~m}^{2}$ network dimension. It can be noticed from the obtained results in Table 1 that increasing the initial energy will increase the average number of the running nodes due to extending the life time of the sensor node. However, it can be noticed that increasing the initial energy to 10 Joule caused a degradation in the number of running nodes.

Scenario 2: (running nodes 150) network size 100x100.

This scenario presents the results obtained in the case of changing the initial energy in the case of considering 150 sensor nodes in the field and in the case of 100x100 m2 network dimension.

Scenario 3: (running nodes 50) network size 100x100.

This scenario presents the results obtained in the case of changing the initial energy in the case of considering 50 sensor nodes in the field and in the case of 100x100 m2 network dimension.

Scenario 4: (running nodes 100) network size 50x50.

This scenario presents the results obtained in the case of changing the initial energy in the case of considering 100 sensor nodes in the field and in the case of $50 \times 50 \mathrm{~m}^{2}$ network dimension.

Scenario 5: (running nodes 150) network size 50x50.

This scenario presents the results obtained in the case of changing the initial energy in the case of considering 150 sensor nodes in the field and in the case of $50 \times 50 \mathrm{~m}^{2}$ network dimension.

Scenario 6: (running nodes 50) network size 50x50.

This scenario presents the results obtained in the case of changing the initial energy in the case of considering 50 sensor nodes in the field and in the case of 50x50 m 2 network dimension.

Scenario 7: (running nodes 100) network size 150x150.

This scenario presents the results obtained in the case of changing the initial energy in the case of considering 100 sensor nodes in the field and in the case of $150 \times 150 \mathrm{~m}^{2}$ network dimension. 
Scenario 8: (running nodes 150) network size 150x150.

This scenario presents the results obtained in the case of changing the initial energy in the case of considering 100 sensor nodes in the field and in the case of $150 \times 150 \mathrm{~m}^{2}$ network dimension.

Scenario 9: (running nodes 50) network size 150x150.

This scenario presents the results obtained in the case of changing the initial energy in the case of considering 50 sensor nodes in the field and in the case of $150 \times 150 \mathrm{~m}^{2}$ network dimension. It can be noticed in this scenario that the overall number of sensor nodes for the different initial energies are less than those for the other scenarios. This is due to the large size of the network and the small size of the available sensor nodes, which affect the number of the operational nodes in the network. Figure 2 shows the wireless sensor network for the case of initial energy $=5$ Joule.

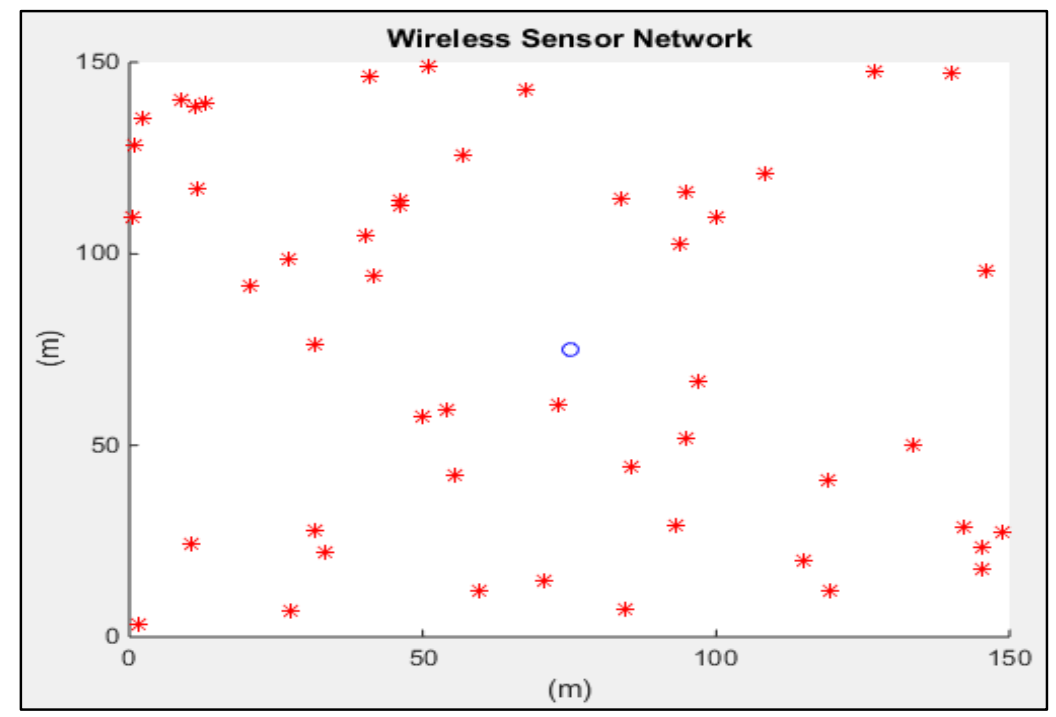

Figure 2. Wireless sensor network (scenario 9 - initial energy $=5$ Joule)

\subsection{The effect of changing the network size on the overall performance}

This section studies the effect of changing the network size on the overall performance of the wireless sensor network taking into consideration different values of the initial energies. This kind of results helps to indicate and understand the impact of the actually used sensor nodes with respect to the area of the sensor network. It can be noticed from the results that increase the network size had led to reducing the number of running nodes, this is due to increasing the distance between the nodes from the sink. This is proportional to increasing the initial power from the running nodes as shown in Figures 3-7.

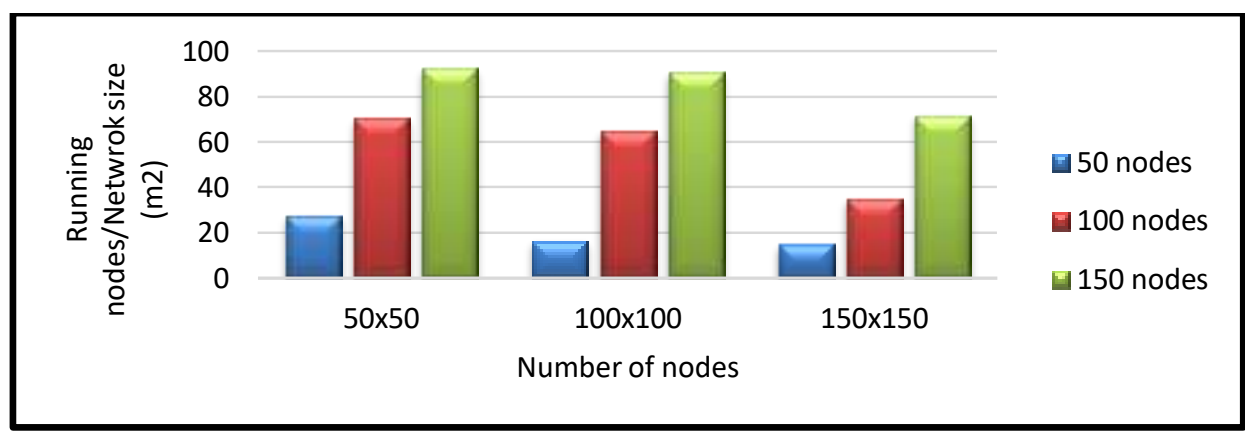

Figure 3. The effect of changing the network size on the running nodes - initial energy $=0.1$ Joule 


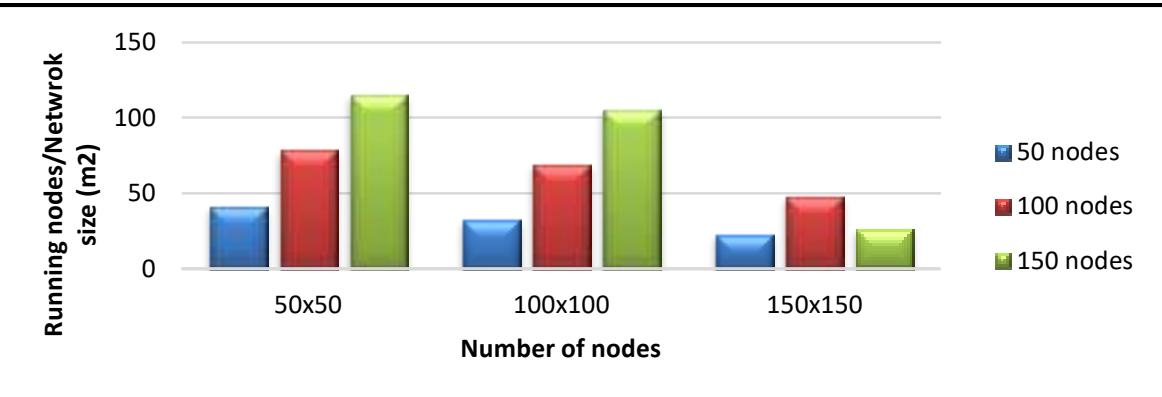

Figure 4 . The effect of changing the network size on the running nodes - initial energy $=2$ Joule

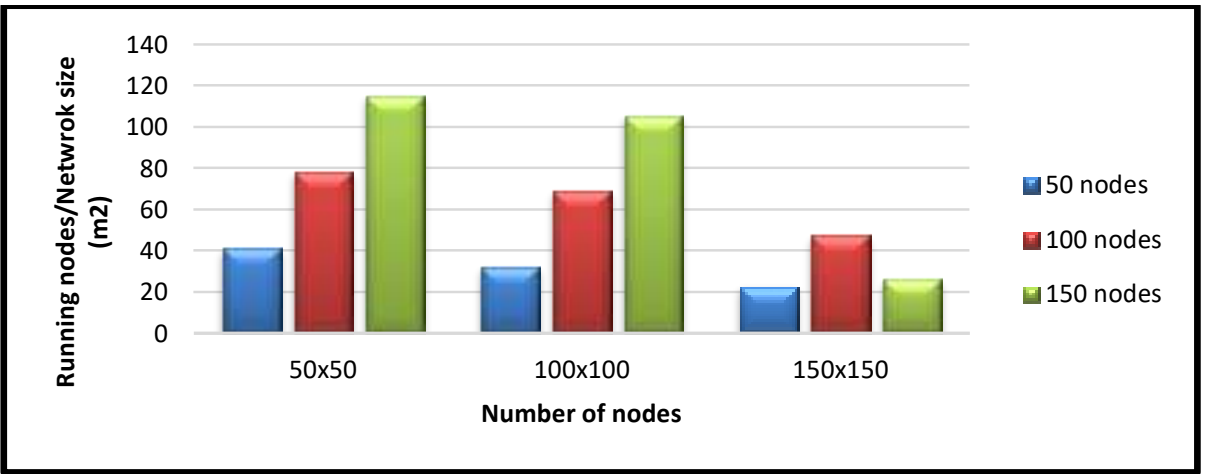

Figure 5 . The effect of changing the network size on the running nodes - initial energy $=5$ Joule

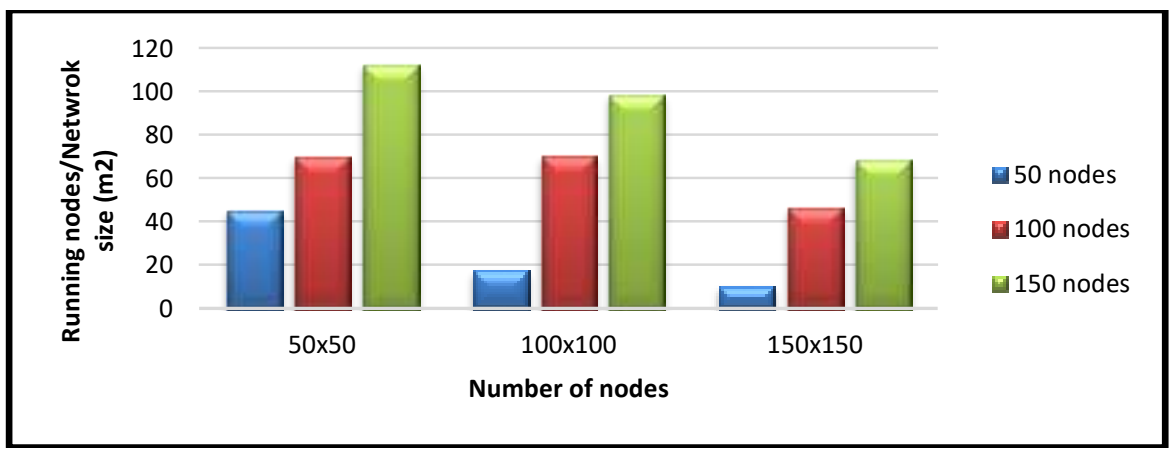

Figure 6 . The effect of changing the network size on the running nodes - initial energy $=7$ Joule

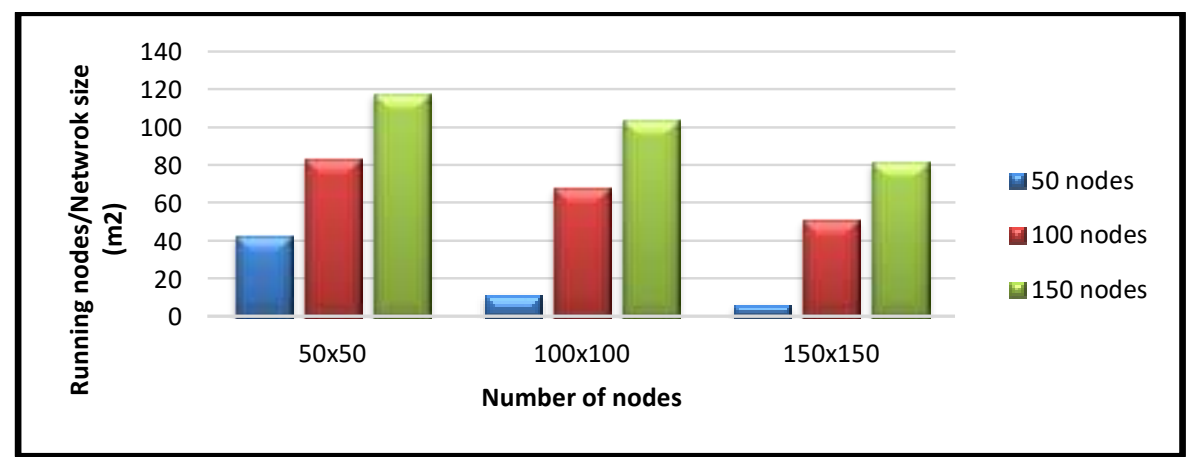

Figure 7. The effect of changing the network size on the running nodes - initial energy $=10$ Joule 
Table 1. Summarizes the running nodes/rounds, running nodes/transmission, and the consumend energy for scenarios (1-9) with different initial energies

\begin{tabular}{|c|c|c|c|c|c|c|c|}
\hline \multirow[t]{2}{*}{ Scenario } & \multirow{2}{*}{$\begin{array}{l}\text { Initial } \\
\text { Energy }\end{array}$} & \multicolumn{2}{|c|}{$\begin{array}{c}\text { Operational } \\
\text { nodes/Rounds }\end{array}$} & \multicolumn{2}{|c|}{$\begin{array}{c}\text { Operational } \\
\text { nodes/Transmission }\end{array}$} & \multicolumn{2}{|c|}{ Consumed Energy } \\
\hline & & Max & Mean & Max & Mean & Max & Mean \\
\hline & 0.1 & 100 & 31.15 & 100 & 74.63 & 0.1876 & 0.08051 \\
\hline Scenario 1 & 2 & 100 & 64.87 & 100 & 83.98 & 0.3088 & 0.0846 \\
\hline$($ running nodes $=100)$ & 5 & 100 & 65.97 & 100 & 84.03 & 0.278 & 0.08123 \\
\hline \multirow[t]{3}{*}{ network size (100x100) } & 7 & 100 & 70.37 & 100 & 84.83 & 0.2705 & 0.08118 \\
\hline & 10 & 100 & 68.22 & 100 & 83.89 & 0.272 & 0.0845 \\
\hline & 0.1 & 150 & 96.03 & 150 & 125 & 0.1708 & 0.0998 \\
\hline Scenario 2 & 2 & 150 & 90.87 & 150 & 131.4 & 0.2934 & 0.1011 \\
\hline (running nodes $=150)$ & 5 & 150 & 67.86 & 150 & 127.8 & 0.4371 & 0.1032 \\
\hline \multirow[t]{3}{*}{ network size $(100 \times 100)$} & 7 & 150 & 98.61 & 150 & 132.2 & 0.3943 & 0.1055 \\
\hline & 10 & 150 & 103.6 & 150 & 134.9 & 0.4123 & 0.1021 \\
\hline & 0.1 & 50 & 10.18 & 50 & 31.06 & 0.1298 & 0.05175 \\
\hline Scenario 3 & 2 & 50 & 16.67 & 50 & 33.9 & 0.1402 & 0.05858 \\
\hline$($ running nodes $=50)$ & 5 & 50 & 18.01 & 50 & 34.04 & 0.1256 & 0.05876 \\
\hline \multirow[t]{3}{*}{ network size $(100 \times 100)$} & 7 & 50 & 17.63 & 50 & 32.89 & 0.1329 & 0.05847 \\
\hline & 10 & 50 & 11.56 & 50 & 31.21 & 0.1521 & 0.060403 \\
\hline & 0.1 & 100 & 45.82 & 100 & 82.26 & 0.07818 & 0.05105 \\
\hline Scenario 4 & 2 & 100 & 70.62 & 100 & 92.63 & 0.1024 & 0.05149 \\
\hline$($ running nodes $=100)$ & 5 & 100 & 81.05 & 100 & 95.77 & 0.1013 & 0.05268 \\
\hline \multirow[t]{3}{*}{ network size $(50 \times 50)$} & 7 & 100 & 70.01 & 100 & 92.93 & 0.09922 & 0.05112 \\
\hline & 10 & 100 & 83.46 & 100 & 92.75 & 0.1031 & 0.05101 \\
\hline & 0.1 & 150 & 84.22 & 150 & 124.7 & 0.0651 & 0.09327 \\
\hline Scenario 5 & 2 & 150 & 92.73 & 150 & 137.4 & 0.1498 & 0.0723 \\
\hline$($ running nodes $=150)$ & 5 & 150 & 113.5 & 150 & 136.2 & 0.1462 & 0.07126 \\
\hline \multirow[t]{3}{*}{ network size $(50 \times 50)$} & 7 & 150 & 112.4 & 150 & 136.4 & 0.1551 & 0.07131 \\
\hline & 10 & 150 & 117.9 & 150 & 138.3 & 0.1546 & 0.07212 \\
\hline & 0.1 & 50 & 25.31 & 50 & 40.69 & 0.0459 & 0.0295 \\
\hline Scenario 6 & 2 & 50 & 27.47 & 50 & 45.13 & 0.0577 & 0.03085 \\
\hline (running nodes $=50)$ & 5 & 50 & 32.26 & 50 & 46.86 & 0.0517 & 0.02946 \\
\hline \multirow[t]{3}{*}{ network size $(50 \times 50)$} & 7 & 50 & 45.14 & 50 & 47.95 & 0.04993 & 0.02936 \\
\hline & 10 & 50 & 42.73 & 50 & 47.56 & 0.04897 & 0.03032 \\
\hline & 0.1 & 100 & 64.57 & 100 & 75.7 & 0.4376 & 0.1255 \\
\hline Scenario 7 & 2 & 100 & 34.99 & 100 & 66.4 & 0.3968 & 0.1272 \\
\hline$($ running nodes $=100)$ & 5 & 100 & 41.94 & 100 & 69.74 & 0.5011 & 0.1348 \\
\hline \multirow[t]{3}{*}{ network size $(150 \times 150)$} & 7 & 100 & 64.18 & 100 & 65.37 & 0.6376 & 0.1413 \\
\hline & 10 & 100 & 51.29 & 100 & 68.52 & 0.6004 & 0.1285 \\
\hline & 0.1 & 150 & 61.52 & 150 & 84.79 & 0.4706 & 0.1533 \\
\hline Scenario 8 & 2 & 150 & 71.83 & 150 & 108.6 & 0.5734 & 0.1578 \\
\hline$($ running nodes $=150)$ & 5 & 150 & 78.25 & 150 & 112.2 & 0.734 & 0.1532 \\
\hline \multirow[t]{3}{*}{ network size (150x150) } & 7 & 150 & 68.68 & 150 & 110.2 & 0.8123 & 0.1489 \\
\hline & 10 & 150 & 81.9 & 150 & 117.5 & 0.8906 & 0.1565 \\
\hline & 0.1 & 50 & 17.4 & 50 & 26.05 & 0.243 & 0.1062 \\
\hline Scenario 9 & 2 & 50 & 14.96 & 50 & 29.16 & 0.2855 & 0.1017 \\
\hline$($ running nodes $=50)$ & 5 & 50 & 16.1 & 50 & 27.87 & 0.2913 & 0.1016 \\
\hline \multirow{2}{*}{ network size (150x150) } & 7 & 50 & 10.28 & 50 & 27.6 & 0.3027 & 0.09858 \\
\hline & 10 & 50 & 6.603 & 50 & 23.92 & 0.2925 & 0.1019 \\
\hline
\end{tabular}

\section{CONCLUSION}

Through the improvement of communication and processor technology, wireless sensor networks are becoming a strong opposition against the wired network. It has also been shown that the effective parameters of wireless networks are the power of the transmitted signal; they can cause a degradation of the system performance and can make it unstable. The protocol LEACH has been designed to improve the lifetime, latency and reliability through discovering multiple paths between the source and the sink. More than one routing paths are available for data transmission. If one path fails, an alternate path is used to transmit the data. The results showed the effect of increasing the initial energy on the overall number of the running nodes in the WSN. It has also been approved that the size of the wireless network could affect the transmission of the data in the WSN. Studying the performance of the WSN can be extended in the future 
work from a simulation to consider a real implementation of the environment taking into consideration the studied parameters.

\section{REFERENCES}

[1] Hussien, Anas Ali, and Muntaha Jameel Eidan, "Automatic ZigBee-Based Wireless Sensor Network for Real Time Temperature Control," International Journal of Wireless Communication and Networking Technology, vol. 4, no. 4 July 2015.

[2] Hussien, Anas A. and Matloob, Safa I., "The Comparative Study Some of Reactive and Proactive Routing Protocols in The Wireless Sensor Network," Journal of University of Babylon for Engineering Sciences, vol. 26, no. 4, pp. 195-207, February 2018.

[3] Qian Liao, Hao Zhu, "An Energy Balanced Clustering Algorithm Based on LEACH Protocol," Proceedings of the 2nd International Conference On Systems Engineering and Modeling (ICSEM-13), 2013.

[4] Vishwakarma, Sangita, "An analysis of LEACH Protocol in Wireless Sensor Network: A Survey," International Journal of Computer Science \& Engineering Technology, vol. 6, no. 3, pp. 148-154, March 2015.

[5] Lalita Yadav1, Ch. Sunitha, Lalita Yadav, "Low Energy Adaptive Clustering Hierarchy in Wireless Sensor Network (LEACH)," International Journal of Computer Science and Information Technologies, (IJCSIT), vol. 5, no. 3, 2014.

[6] Jose Henrique Brand ' ao Neto, Antoniel da Silva Rego, Andre Ribeiro Cardoso, Joaquim Celestino, "MHLEACH: A Distributed Algorithm for Multi-Hop Communication in Wireless Sensor Networks," ICN 2014: The Thirteenth International Conference on Networks, pp. 55-61, 2014.

[7] Singh S. and Sharma S., "A Survey on Cluster Based Routing Protocols in Wireless Sensor Networks," In Procedia Computer Science, vol. 45, pp. 687- 695, 2015.

[8] Belwal, Monika. "Energy Efficient Leach And Improved Leach: A Review," International Journal of Advanced Research in Computer Science, vol. 10, no. 3, pp. 51-53, pp. 92-96, May 2019.

[9] Kaur, P., and Kad, S., "Energy-efficient routing protocols for wireless sensor network: a review," International Journal of Scientific \& Technolgy Research, vol. 6, no. 12, December 2017.

[10] Rani, Shalli, Jyoteesh Malhotra, and Rajneesh Talwar, "EEICCP-energy efficient protocol for wireless sensor networks," Wireless sensor network, vol. 5, no. 7, pp. 127-136, 2013.

[11] Stephanie Lindsey Cauligi S. Raghavendra,"PEGASIS: Power-Efficient Gathering in Sensor Information Systems," Proceedings, IEEE Aerospace Conference, Big Sky, MT, USA, pp. 3-3, 2002.

[12] Jain T., Saini D., and Bhooshan S., "Lifetime Optimization of a Multiple SinkWireless Sensor Network through Energy Balancing," Journal of Sensors, vol. 2015, pp. 1-6, April 2015.

[13] P. Kuila and P. K. Jana, "Energy Efficient Clustering and Routing Algorithms for Wireless Sensor Networks: Particle Swarm Optimization Approach,” Engineering Applications of Artificial Intelligence, vol. 33, pp. 127-140, August 2014.

[14] Suraj Sharma, "On Energy Efficient Routing Protocols Wireless Sensor Networks," Ph. D. Dissertation, Department of Computer Science and Engineering National Institute of Technology Rourkela Rourkela-769 008, Odisha, India, 2016.

[15] Nishita Payar, Prof. Chandresh R. Parekh, Nishita Payar et al., "Ee-Leach (Low Energy Adaptive Clustering Hierarchy) Modified Protocol," Int. Journal of Engineering Research and Applications, vol. 4, pp. 5-10, May 2014.

[16] Jain T., Saini D., and Bhooshan S., "Lifetime Optimization of a Multiple Sink Wireless Sensor Network through Energy Balancing,” Journal of Sensors, vol. 2015, pp. 1-6, April 2015.

[17] Siva D. Muruganathan, Daniel C. F. Ma, Rolly I. Bhasin, andabraham, Fapojuwo, "A Centralized Energy-Efficient Routing Protocol for Wireless Sensor Networks," in IEEE Communications Magazine, vol. 43, no. 3, pp. S8-13, March 2005.

[18] Prasad, A. Y., and Balakrishna, R., "Implementation of optimal solution for network lifetime and energy consumption metrics using improved energy efficient LEACH protocol in MANET," TELKOMNIKA, vol. 17, no. 4, pp. 1758-1766, August 2019.

[19] Chunyao FU, Zhifang JIANG, Wei WEI and Ang WEI, IJCSI, “An Energy Balanced Algorithm of LEACH Protocol in WSN," International Journal of Computer Science Issues (IJCSI), vol.10, no. 1, pp. 354-359,January 2013

[20] Suraj Sharma, Sanjay Kumar Jena, "Cluster-based Multipath Routing Protocol for Wireless Sensor Networks," ACM SIGCOMM Computer Communication Review, vol. 45, no. 2, pp. 15-20, April 2015.

[21] Ouldzira, H., Lagraini, H., Mouhsen, A., Chhiba, M., \& Tabyaoui, A., "MG-leach: an enhanced leach protocol for wireless sensor network," International Journal of Electrical \& Computer Engineering(IJECE), vol. 9, no. 4, pp. 3139-3145, August 2019.

[22] Kundaliya, B., \& Hadia, S. K., "Enhancing network lifetime with an improved MOD-LEACH," International Journal of Electrical \& Computer Engineering(IJECE), vol. 9, no. 5, pp. 3615-3622, October 2019.

[23] Malik, M., Singh, Y., and Arora, A., "Analysis of LEACH protocol in wireless sensor networks," International Journal of Advanced Research in Computer Science and Software Engineering, vol. 3, no. 2, 2013.

[24] Sharma, B., and Kumar, G., "Performance analysis for qualitative evaluation with comparative study for designing energy efficient algorithm for wireless sensor networks for enhancing lifetime of leach protocol using dynamic simulation as variation in channel probing for opportunistic power saving mechanism for power evaluation and estimation optimization as latest trend used in electronics and communication engineering," Journal Appl Biotechnol Bioeng, vol. 4, no. 3, pp. 622-625, 2017. 
[25] Elhoseny, M., Farouk, A., Zhou, N., Wang, M. M., Abdalla, S., \& Batle, J., "Dynamic multi-hop clustering in a wireless sensor network: Performance improvement," Wireless Personal Communications, vol. 95, no.4, pp. 37333753, March 2017.

\section{BIOGRAPHY OF AUTHORS}

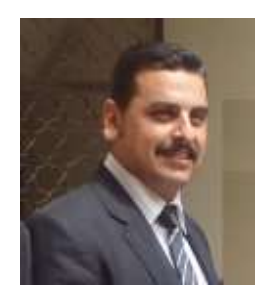

Anas Ali Hussien received the B.Sc. in Electronics and Communications Engineering in 1999, M.Sc. in Electronics and Communications Engineering / Electronic Circuits and Systems in 2001 and Ph.D. in Information Engineering in 2007, from Al-Nahrain University.

He is an associate professor since 2012 and head of the computer-engineering department.

Dr Anas has published more than 12 published papers all of them in reputed journals and conferences

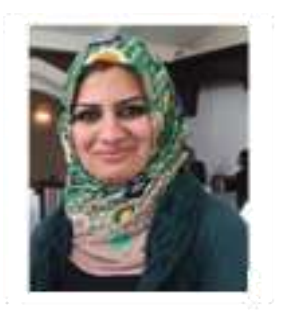

Shaymaa Waleed AlShammari received the B.Sc. in Computer Engineering in 2005, M.Sc. in Computer Engineering in 2008 from Al-Nahrain University, Baghdad, Iraq, and Ph.D. in Computer Engineering / Distributed Systems in 2017 from University of Salford, Manchester, UK.

She is a lecturer in Al-Nahrain University, Baghdad, Iraq since 2008. Her research interests are in the subject of cloud computing, web services, QoS, QoE, network performance and published many papers related to these subjects.

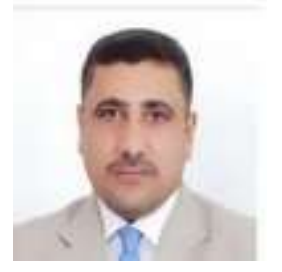

Mehdi J. Marie was born in Baghdad, Iraq in 1970. He received his Bachelor's (1993), Master's (2004) Degrees from University of Technology (Iraq) and Ph. D. from the University of Basrah (2014). He has been a lecturer of Control Theory I, II, Electronics and Electrical Networks at the Al-Nahrain University, College of Engineering. He is currently a senior engineer at Al-Zawaraa State Company, Ministry 